\title{
Pre-contrast ShMOLLI T1 mapping in cardiac AL amyloidosis
}

\author{
Theodoros Karamitsos ${ }^{2 *}$, Sanjay M Banypersad ${ }^{1,3}$, Daniel Sado $^{1}$, Viviana Maestrini ${ }^{1}$, Vanessa Ferreira ${ }^{2}$, \\ Stefan K Piechnik², Matthew D Robson², Philip N Hawkins ${ }^{3}$, Stefan Neubauer ${ }^{2}$, James Moon ${ }^{1}$ \\ From 15th Annual SCMR Scientific Sessions \\ Orlando, FL, USA. 2-5 February 2012
}

\section{Background}

Multi-organ disease with cardiac involvement carries a very poor prognosis in Systemic AL Amyloidosis. The risk of nephrogenic systemic fibrosis is a significant obstacle in assessing cardiac status using CMR in patients with systemic AL amyloidosis who have advanced renal failure. Measurement of myocardial T1 values has been limited until now, due to long breathhold times. We have developed a robust and clinically applicable technique for diagnosing cardiac amyloidosis by measuring absolute myocardial $\mathrm{T} 1$ values using the single breath hold, Shortened Modified Look-Locker Inversion Recovery (ShMOLLI) sequence without gadolinium administration.

\section{Methods}

Thirty-five patients (23 males, 12 females, mean age 60 years) with systemic AL amyloidosis underwent conventional CMR scanning with cine imaging and late gadolinium imaging as well as ShMOLLI pre-contrast T1mapping between both centres; all patients had an eGFR of $>30 \mathrm{ml} / \mathrm{min}$. Myocardial T1 values from the basal septum in the apical 4-chamber view were measured and compared against cardiac biomarkers, and ECG data. Results were compared to normal controls $(n=54)$. Conventional clinical assessment using the Mayo staging system ranked cardiac involvement as definite, probable and none.

\section{Results}

Myocardial T1 was significantly higher in all patients with systemic AL amyloidosis compared to normals (1057 vs $967, \mathrm{P}<0.001$ ). When assessed against pre-test

${ }^{2}$ Dept. of Cardiovascular Medicine, University of Oxford Centre for Clinical Magnetic Resonance Research (OCMR), Oxford, UK

Full list of author information is available at the end of the article probability of cardiac involvement based on clinical evaluation, myocardial $\mathrm{T} 1$ in patients with probable and definite cardiac disease was significantly higher than normals $(\mathrm{P}<0.005)$ (see figure 1$)$. Myocardial T1 correlated linearly with indexed LV mass $\left(\mathrm{R}^{2} 0.21, \mathrm{P}<0.005\right)$, BNP $\left(R^{2} 0.49, P<0.005\right)$ and inversely with ejection fraction $\left(\mathrm{R}^{2} 0.31, \mathrm{P}<0.005\right)$ and $\mathrm{QRS}$ voltage on ECG $\left(\mathrm{R}^{2}\right.$ $0.32, \mathrm{P}<0.005$ ) (see figure 2). Correlations were not observed with markers of functional assessment such as NYHA class and ECOG status, possibly due to confounding variables such as co-existing peripheral neuropathy and degree of fluid overload.

\section{Conclusions}

Using the ShMOLLI sequence to measure absolute myocardial $\mathrm{T} 1$ times in patients with systemic $\mathrm{AL}$

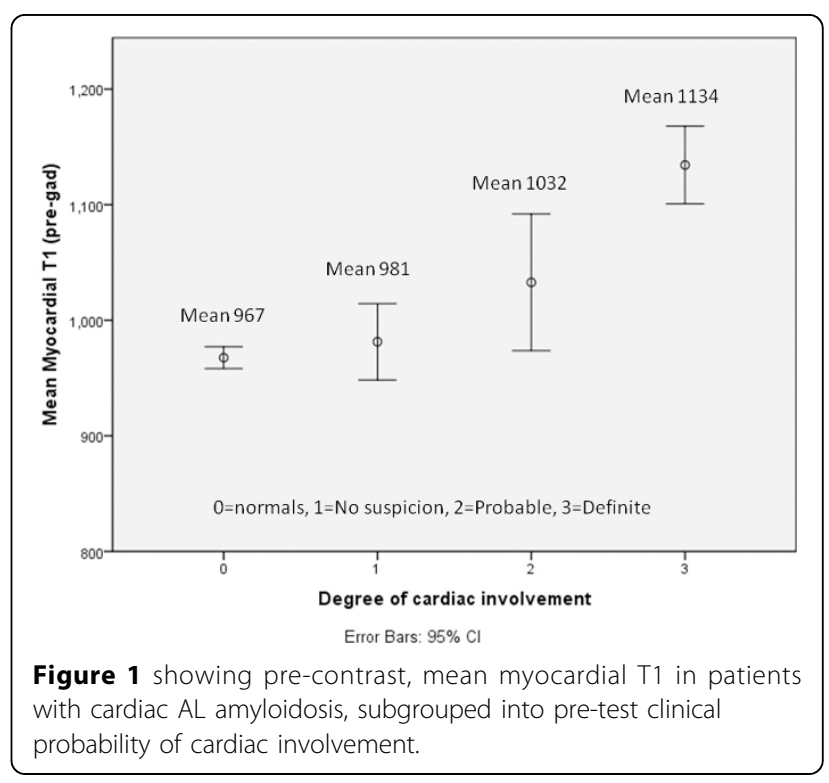




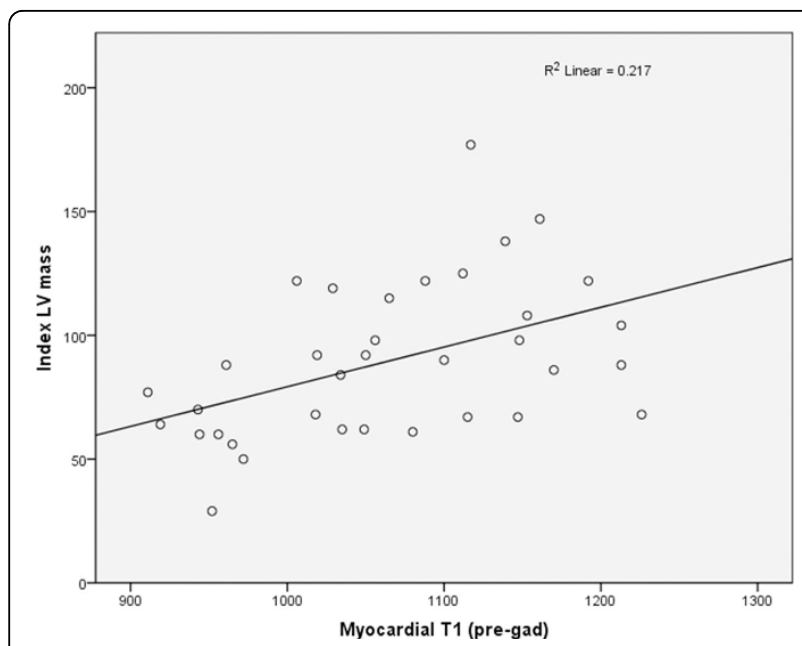

Figure 2 showing the correlation between pre-contrast, mean myocardial T1 by ShMOLLI and mean indexed LV mass.

amyloidosis is a safe and accurate method for determining the presence or otherwise of cardiac involvement by amyloid and it correlates well with currently accepted measures of cardiac dysfunction in amyloidosis.

\section{Funding}

GSK, SKP, VMF, MDR funded by the NIHR Oxford Biomedical Research Centre Programme.

\section{Author details}

${ }^{1} \mathrm{MRI}$, The Heart Hospital, London, UK. ${ }^{2}$ Dept. of Cardiovascular Medicine, University of Oxford Centre for Clinical Magnetic Resonance Research (OCMR), Oxford, UK. ${ }^{3}$ National Amyloidosis Centre, Royal Free Hospital, London, UK

Published: 1 February 2012

doi:10.1186/1532-429X-14-S1-076

Cite this article as: Karamitsos et al:: Pre-contrast ShMOLLI T1 mapping

in cardiac AL amyloidosis. Journal of Cardiovascular Magnetic Resonance 2012 14(Suppl 1):O76.

\section{Submit your next manuscript to BioMed Central} and take full advantage of:

- Convenient online submission

- Thorough peer review

- No space constraints or color figure charges

- Immediate publication on acceptance

- Inclusion in PubMed, CAS, Scopus and Google Scholar

- Research which is freely available for redistribution

Submit your manuscript at www.biomedcentral.com/submit 